\title{
LA METÁFORA DEL DESIERTO EN HANNAH ARENDT*
}

\author{
Sergio Quintero Martín \\ Universidad Nacional Autónoma de México, México \\ squint46664@gmail.com
}

\section{RESUMEN}

Cuando a comienzos de 1955 Hannah Arendt comenzó a indagar sobre los orígenes y las causas de la vida política para la planificación de un libro, que nunca vio la luz y que hubiera llevado el título de Einführung in die Politik (Introducción a la politica), se hizo una pregunta con resonancia en el pensamiento de Leibniz, Schelling y Heidegger: ¿por qué hay alguien y no más bien nadie? Con esta pregunta Arendt se hace eco de un fenómeno que atravesaría el conjunto de su pensamiento: el extrańamiento del mundo (Weltentfremdung), que se extendía entre los filósofos como un mal endémico a la hora de analizar las condiciones del mundo. Para Arendt este fenómeno representa el primer obstáculo a salvar para comprender la realidad de la política. La actualidad del fenómeno de lo político, prestando especial atención a la metáfora del desierto y cómo a partir de ésta se desglosa la relación entre la tiranía y el vaciamiento del espacio público.

Palabras Clave: desierto, oasis, extrañamiento del mundo, animal laborans, Homo faber.

\section{THE METAPHOR OF THE DESERT \\ IN HANNAH ARENDT}

\section{Abstract}

At the beginning of 1955 Hannah Arendt began to inquire into the origins and causes of political life for the planning of a book, which never saw the light and which would have borne the title Einführung in die Politik (Introduction to Politics), she asked herself a question with resonance in the thought of Leibniz, Schelling and Heidegger: Why is there someone and not rather no one? With this question Arendt echoes a phenomenon that would run through the whole of her thought: the estrangement from the world (Weltentfremdung), which was widespread among philosophers as an endemic disease when analyzing the conditions of the world. For Arendt this phenomenon represents the first obstacle to overcome in order to understand the reality of politics. The actuality of the political phenomenon, paying special attention to the metaphor of the desert and how it breaks down the relationship between tyranny and the emptying of public space.

KeYwords: Desert, Oasis, Weltentfremdung, animal laborans, Homo faber. 


\section{LA METÁFORA DEL DESIERTO}

En su tesis doctoral, El concepto de amor en San Agustín (1929), Hannah Arendt hace uso por primera vez la metáfora del desierto. Esta metáfora apunta a la especial vinculación del fenómeno de lo político con el espacio y posee un potente eco con la cultura judía. Pone de manifiesto la actualidad de lo que Antonio Campillo ${ }^{1}$ denomina como los procesos históricos de despolitización y repolitización.

Si pudiera decirse del hombre que tiene alguna naturaleza esencial, sería el hecho de no ser autosuficiente. De aquí que el hombre se vea empujado a quebrar este aislamiento por el amor -sea que cupiditas haga de él un habitante de este mundo, sea que caritas le haga vivir en el futuro absoluto como habitante del mundo por venir-. Solo el amor llega a constituir uno de ambos mundos en hogar del hombre, y por tanto "para los creyentes [que no aman el mundo] este mundo es lo que el desierto era para el pueblo de Israel»: en él no viven en casas sino en tiendas. ¿No sería entonces mejor vivir en cupiditas y tener un hogar en el mundo? ¿Por qué habría que hacer de este mundo un desierto? La justificación de esta extraordinaria empresa solo puede estar en la profunda insatisfacción de quienes aman el mundo, para con lo que el mundo puede darles².

A pesar de que Arendt apunte a que fue Friedrich Nietzsche $e^{3}$ «el primero que reconoció que vivimos y nos movemos en un mundo desértico» ${ }^{4}$, así mismo también fue el propio filósofo de Röcken quien primeramente erró en el diagnóstico sobre la existencia del desierto. El desierto no es la forma auténtica del mundo, sino la transformación esperpéntica en la que habitamos, pero, como apropiadamente apunta Arendt, estar condenados a vagar por el desierto, en analogía al éxodo judío, no nos convierte de facto en sus habitantes.

La interpretación nietzscheana del desierto induce a creer que es algo que está en nosotros, haciéndonos no solo sus habitantes conscientes sino también partícipes de su más cruel espejismo: creer que el mundo es, ha sido y será siempre un desierto. Esta percepción se mantiene, según Arendt, debido a la psicología moderna, puesto que continúa con esta inversión en la percepción del desierto. Esta falsa sensación de

* Este trabajo ha sido desarrollado como parte de mi investigación posdoctoral y gracias al apoyo y el financiamiento de la Dirección General de Asuntos del Personal Académico (DGAPA) de la Universidad Nacional Autónoma de México (UNAM), estando adscrito a la Facultad de Filosofía y Letras. Asimismo, quiero reiterar mis agradecimientos a mi asesora, la Dra. Griselda Gutiérrez Castañeda, por su colaboración e inestimable ayuda, sin la cual este proyecto no hubiera salido adelante.

${ }^{1}$ Campillo, A., El concepto de lo político en la sociedad global, Barcelona, Herder, 2008, p. 254.

2 Arendt, H., El concepto de amor en San Agustín (trad. Agustín Serrado de Haro), Madrid, Encuentro, 2001, p. 37. Las puntualizaciones en subrayado son propias.

${ }^{3}$ Véase, Nietzsche, F., Asi habló Zaratustra (trad. Andrés Sánchez Pascual), Madrid, Alianza, 2007.

4 Arendt, H., «Del desierto y los oasis» (trad. Agustín Serrano de Haro). Revista de Occidente, 305, 2006, p. 99. 
habitabilidad del desierto arrebata a los seres humanos su valor qua seres humanos y los deshumaniza por medio de actividades reificantes. La ayuda que recibiríamos de la psicología sería para adaptarnos a la vida en el desierto. Sin embargo, la cuestión es esencialmente la opuesta, como afirma la propia Arendt: «Precisamente porque sufrimos bajo las condiciones del desierto todavía somos humanos y aún seguimos intactos; el peligro está en llegar a ser verdaderamente habitantes del desierto y en sentirse en él como en nuestra casan.

Arendt es propensa a presentar su reflexión sobre la realidad en términos espaciales, recurriendo a este tipo de figuras literarias y teatrales o ejemplos históricos (la polis griega, la Comuna de París, los kibutzim judíos, el People’s Park). En este caso, la metáfora del desierto es un buen ejemplo: presenta el mundo como un lugar inhóspito y estéril que suplanta y transfigura el potencial político del espacio público. Se trata de una imagen muy potente. Por medio de esta metáfora compone una explicación y un primer intento de comprensión del fenómeno que le preocupó toda la vida: el extrañamiento o enajenación del mundo.

El recurso de esta metáfora es empleado por parte de Arendt en múltiples ocasiones. Podemos comprobarlo en diversos textos preparatorios ${ }^{6}$ como Ideología $y$ terror $^{7}$ (1953), las notas y los fragmentos para la obra no publicada de Einführung in die Politik (Introducción a la politica) $)^{8}$, el escrito Del desierto y los oasis $(1955)^{9}$, y varias entradas en Diario filosófico (2018). No obstante, para Arendt el uso de la metáfora no es un simple adorno o floritura para embellecer el texto. La metáfora representa una herramienta esencial para la comprensión porque es el punto de encuentro entre el pensamiento y la acción por medio de la agitación de la imaginación.

A pesar de que Arendt remarca el origen poético de la metáfora, hace hincapié en que se trata del mejor regalo que el lenguaje hizo al pensamiento y, por ende, a la filosofía. Es en su obra póstuma, La vida del espíritu (1978), donde Arendt

5 Arendt, H., La promesa de la política (Ed. Jerome Kohn) (trad. Eduardo Cańas y Fina Birulés), Barcelona, Austral, 2016b, p. 225.

${ }^{6}$ Debemos recordar en este punto que en el método de preparación de sus obras Arendt realizaba una voluminosa cantidad de anotaciones en su diario filosófico, ensayos breves, conferencias y textos complementarios, tanto previos para presentar las ideas de lo que quería decir como posteriores para matizarlas y realizar correcciones.

7 Este ensayo que originariamente fue un Festschrift o texto conmemorativo por el setenta cumpleaños de su maestro Karl Jaspers se incluyó posteriormente en su obra magna, Los orígenes del totalitarismo (1951), como capítulo final en la tercera parte (Totalitarismo) de la segunda edición de 1958.

${ }^{8}$ En 1993 la socióloga alemana Ursula Ludz, a petición de la editorial Piper, se encargó de compilar estos materiales y se publicaron como obra póstuma de Arendt bajo el título Was ist Politik? (1993). La edición en español, titulada ¿Qué es la política? (1997), corre a cargo de la profesora Fina Birulés, con la traducción realizada por Rosa Sala Carbó.

9 Este texto forma parte de las conclusiones que Arendt dictó en la Universidad de Berkeley como parte del curso Historia de la teoría politica, que impartió en 1955. Actualmente se encuentra como Prefacio en la obra compilatoria que realizó Jerome Kohn sobre diversos textos de Arendt y titulada La promesa de la política (2005). A su vez, en español se encuentra traducido por Agustín Serrado de Haro y publicado de manera independiente en Revista de Occidente (305). 
resalta el valor y la relevancia epistémica del lenguaje metafórico por cuanto se trata de la herramienta que nos permite «salvar el abismo entre las actividades mentales interiores e invisibles y el mundo de las apariencias» ${ }^{10}$. La metáfora favorece la comprensión porque tiene la capacidad de unir ambos mundos y permite pensar, estimulando la imaginación, en implicaciones más allá de los límites del propio concepto.

La metáfora proporciona a «lo abstracto», al pensamiento sin imágenes, una intuición procedente del mundo de las apariencias, cuya función es «exponer la realidad de nuestros conceptos» y deshacer, por así decirlo, la retirada del mundo de las apariencias que es la precondición de las actividades mentales ${ }^{11}$.

El aspecto que vertebra el uso de la metáfora del desierto a lo largo de la obra arendtiana es el establecimiento de la relación entre la tiranía y el espacio público. Se trata de una relación inversa: cuanto mayor es el poder tiránico, usualmente por medio del terror, menor es el espacio público disponible. Se produce un vaciamiento progresivo del espacio para la toma de decisiones y la participación política. Como consecuencia, se apaga la potencialidad política del espacio vinculante que se crea a través de la dimensión relacional de los seres humanos.

Hoy, después del fracaso del experimento imperialista y bajo el signo de la amenaza total y totalitaria, tenemos Estados detrás de los cuales ya no está el pueblo, territorios cuyos habitantes ya no quieren defenderlos frente a conquistadores extraños, y pueblos que ni están organizados y protegidos por el Estado, ni están «radicados» en el suelo. Éste es el espacio del desierto, en el que se desencadenan las tormentas de arena ${ }^{12}$.

El tiempo de desertificación que describe Arendt sitúa a los seres humanos en un abismo cualitativo que los divide y aleja entre sí. Se impone una jerarquía antropológica apoyada en una supuesta igualdad natural centrada en la igual pertenencia al desierto. El aspecto más peligroso que se revela de la vida en el desierto se encuentra en que lo que se destruye en el mundo puede volver a renacer, en cambio lo desertificado no. El desierto no solo destruye, sino que imposibilita el renacimiento. El crecimiento del desierto representa la progresiva imposibilidad de recuperar la potencialidad política de los espacios relacionales.

${ }^{10}$ Arendt, H., La vida del espiritu (trad. Carmen Corral y Fina Birulés), Barcelona, Paidós, 2016c, p. 128.

11 Arendt, H., La vida del espiritu (trad. Carmen Corral y Fina Birulés), Barcelona, Paidós, 2016c, p. 125.

12 Arendt, H., Diario filosófico 1950-1973 (Ed. Ursula Ludz e Ingeborg Nordmann) (trad. Raúl Gabás), Barcelona, Herder, 2018, p. 208. 
Como sostiene Arendt, «el desierto no está "en" los hombres, sino entre los hombres» ${ }^{13}$. De manera análoga a como sucede con los espacios vinculantes y su potencial político: los seres humanos no son seres políticos, la política «nace en el Entre-los-hombres ${ }^{14}$. Esta irreductibilidad de la potencialidad política que muestra la dimensión relacional de los seres humanos es lo que se encuentra en pugna con el avance del desierto.

La creación típicamente moderna del mundo-desierto es el lugar que queda tras la disolución del mundo de las relaciones humanas, lo que Arendt denominó como Zwischenwelt. La cuestión determinante del desierto es que transforma los fecundos espacios vinculantes, elimina su potencial significado político y los vuelve terrenos yermos ${ }^{15}$. La falta de resistencia frente a este vaciamiento de la vida pública, propio de la tiranía, permite que los seres humanos se adapten progresivamente a vivir en el desierto.

La consideración moderna de la política, que denominaremos como política epistemológica y originada a partir de la invención histórica del Estado, instituyó una concepción restringida del fenómeno de lo político ${ }^{16}$. Esta nueva concepción de la política se apoya en cuatro pilares: 1) la especial relación con la violencia, 2) la propiedad privada, 3) las clases sociales, y 4) la dominación patriarcal, bajo lo que Campillo ${ }^{17}$ considera como la triple condición de padres, patronos y patriotas. La red de relaciones necesarias para llevar a cabo esta visión restringida de la política fue presentada por Friedrich Engels en su obra El origen de la familia, la propiedad privada y el estado (1884). En nuestra reflexión destacaremos brevemente la relación con la violencia.

La política moderna alcanzó su cénit con el surgimiento del imperialismo, fruto de la colonización. En términos arendtianos esta conceptualización de la política no es política en absoluto, sino una nueva forma de dominación e imposición: es la tiranía del más fuerte. Se trata de una visión de la política más en sintonía con Carl von Clausewitz que con la propia Arendt. Es en este punto cuando los espacios vinculantes comienzan a desertificarse y avanzar en el mundo.

El poder que rige en el desierto es el poder ad baculum. Un poder que, lejos de unir y componer un espacio para las relaciones, las disuelve. En su lugar se forma un espacio conformado por el temor, la animadversión a la diferencia y las relacio-

13 Arendt, H., Diario filosófico 1950-1973 (Ed. Ursula Ludz e Ingeborg Nordmann) (trad. Raúl Gabás), Barcelona, Herder, 2018, p. 522.

${ }_{14}$ Arendt, H., ¿Qué es la política? (Ed. Fina Birulés) (trad. Rosa Sala Carbó), Barcelona, Paidós, 2015, p. 46.

${ }^{15}$ Straehle, E., «De parques, plazas y oasis: una exploración de los espacios políticos en Hannah Arendt». Las Torres de Lucca, 10, 2017, p. 36.

${ }^{16}$ Campillo, A., El concepto de lo político en la sociedad global, Barcelona, Herder, 2008, p. 259.

17 Cf. Campillo, A. El concepto de lo politico en la sociedad global, Barcelona, Herder, 2008. 
nes basadas en las diferentes formas de violencia. El objetivo se torna en tiranizar a los otros, apelando a la dialéctica schmittiana del amigo-enemigo. Como consecuencia, el desierto aísla y progresivamente envenena al ser humano, lo cubre de desconfianza y filisteísmo ${ }^{18}$.

No debemos olvidar que «Arendt consideraba que el mundo se torna inhumano, inhóspito a las necesidades humanas, cuando se lo empuja con violencia hacia un movimiento en el que ya no existe ninguna forma de permanencia ${ }^{19}$. La tiranía tiene la capacidad de vaciar y disolver el potencial político de los espacios vinculantes porque elimina la posibilidad de construir un proyecto de vida común que no apele a la violencia y la guerra para su constitución.

Las guerras que financia el imperialismo están lejos de la política exterior de la lex romana creadora de vínculos entre los pueblos ${ }^{20}$, son guerras de aniquilación. La política moderna, apoyada en la consideración clausewitziana de que la guerra es la continuación de la política por otros medios, devasta la posibilidad de establecer un vínculo (o espacio vinculante) entre vencedores y vencidos, y desertifica el mundo qua mundo. Como afirma Arendt: «lo aniquilado en una guerra de este tipo es mucho más que el mundo del rival vencido; es sobre todo el espacio entre los combatientes y entre los pueblos, espacio que en su totalidad forma el mundo sobre la Tierra ${ }^{21}$.

Lejos de acabar ahí la desertificación, el imperialismo cristalizó en torno a la culminación patológica de la subjetivación del poder: el totalitarismo. El fenómeno del totalitarismo, en lugar de hacer desaparecer el desierto, lo avivó. Aprovechó el lugar que había construido la tiranía, este mundo-desierto, como punto de partida para alcanzar cotas de deshumanización impensables para la política moderna en sus orígenes. Para hablar de las catastróficas consecuencias que tiene el totalitarismo para el desierto, Arendt emplea una nueva metáfora: las tormentas de arena.

La arena del desierto convierte, por un lado, la acción y la capacidad de juzgar en un conductismo social basado en la repetición de patrones y protocolos estandarizados y, por otro lado, la dimensión relacional de los seres humanos se torna en relaciones de dominación y violencia centradas más en la supervivencia individual ante un entorno hostil que en la cooperación conjunta para revertir el desierto. Ade-

${ }_{18}$ Arendt habla del hombre filisteo y del filisteísmo en términos modernos en el sentido de philistin, es decir, como "la persona de gusto vulgar, cerrada a las artes, a las letras y a las novedades" (Cf. Bourdieu, P., La distinción. Criterio y bases sociales del gusto [trad. María del Carmen Ruiz de Elvira], Ciudad de México, Taurus, 2002, p. 9). En palabras de Arendt: «Ser un filisteo, un hombre adherido a la banausia, a la vulgaridad, indicaba entonces y ahora una mentalidad exclusivamente utilitaria, una incapacidad de pensar y juzgar las cosas como no sea por su función o utilidad" (Cf. Arendt, H., Entre el pasado y el futuro: ocho ejercicios sobre la reflexión politica [trad. Ana Poljak], Barcelona, Península, 1996, p. 227).

19 Birulés, F., Una herencia sin testamento: Hannah Arendt, Barcelona, Herder, 2007, p. 234.

20 Arendt, H., ¿Qué es la política? (Ed. Fina Birulés) (trad. Rosa Sala Carbó). Barcelona, Paidós, 2015.

${ }^{21}$ Arendt, H., ¿Qué es la política? (Ed. Fina Birulés) (trad. Rosa Sala Carbó). Barcelona, Paidós, 2015, p. 129. 
más, la arena no solo transforma el presente, sino que afecta al futuro, puesto que busca convertir las promesas políticas en lugares fijos de llegada, algo que va en contra de la vulnerabilidad y la impredecibilidad de la acción. Es decir, no solo arruina la posibilidad de la caritas, sino también de la propia cupiditas.

En su punto más elevado el totalitarismo pretende llevar a los seres humanos a la impotencia absoluta, impidiéndoles actuar, juzgar y relacionarse. En otras palabras, transmuta la pluralidad en una masa de egos conformistas. El avance del desierto es implacable y solo habla el idioma del amigo al que ha sometido y del enemigo al que ha aplastado.

Como los movimientos totalitarios provienen de una cristalización del imperialismo (entre otros mecanismos), es decir, como las tormentas de arena nacen del desierto, éstos parecen las mejores formas políticas de habitar en él. Sin embargo, «lejos de ser causado por la vida política pública, el desierto es el resultado de su ausencia $\aleph^{22}$. Igual que sucedía con la psicología moderna, el totalitarismo continúa invirtiendo la percepción sobre el desierto y perpetúa su falsa sensación de habitabilidad.

Lo que hace posible la efectividad de la ficción totalitaria es la recursión al terror. "La filosofía del terror devino en "un tipo de expresionismo político" ${ }^{23}$ que compone un mundo cualitativamente diferente al presentado por el miedo o el temor de la tiranía moderna. El fenómeno del totalitarismo «lejos de conformarse con anular el movimiento de los otros, lo que prefiere es movilizarlos de manera permanente con el objeto de impedir que se puedan reunir en un espacio concreto» ${ }^{24}$. Como vemos, el totalitarismo va más allá de la desertificación propia de la tiranía. La propia Arendt lo describe de la siguiente manera en Los orígenes del totalitarismo (1951):

Presionando a los hombres unos contra otros, el terror total destruye el espacio entre ellos; en comparación con las condiciones existentes dentro de su anillo de hierro, incluso el desierto de la tiranía parece como una garantía de libertad en cuanto que todavía supone algún tipo de espacio. El gobierno totalitario no restringe simplemente el libre albedrío y arrebata las libertades [...]. Destruye el único prerrequisito esencial de todas las libertades, que es simplemente la capacidad de movimiento, que no puede existir sin espacio ${ }^{25}$.

Las tormentas de arena azotan el desierto para enardecer su avance y su proliferación. Reducen la visibilidad de lo que rodea a los seres humanos y la viabilidad de establecer lazos. Estas tempestades los aíslan y los condenan a deambular solos

${ }^{22}$ Kohn, J., «Introducción», en Hannah Arendt, La promesa de la política (Ed. Jerome Kohn) (trad. Eduardo Cañas y Fina Birulés) (pp. 11-37), Barcelona, Austral, 2016, p. 35.

${ }^{23}$ Moran, D., «Hannah Arendt. La fenomenología de la esfera pública», en Dermot Moran, Introducción a la Fenomenología (Ed. Gustavo Leyva) (trad. Francisco Castro Merrifield y Pablo Lazo Briones) (pp. 270-300), Barcelona, Anthropos, 2011, p. 283.

${ }_{24}$ Straehle, E., «De parques, plazas y oasis: una exploración de los espacios políticos en Hannah Arendt». Las Torres de Lucca, 10, 2017, p. 37.

${ }^{25}$ Arendt, H., Los origenes del totalitarismo (trad. Guillermo Solana), Madrid, Alianza, 20202, p. 624 . 
por una tierra inhóspita, aterrados ante la posibilidad de conectar los unos con los otros por temor a las represalias. La arena del desierto en movimiento envuelve a los seres humanos, atomizando la realidad perceptible y convirtiéndolos paulatinamente en nadie. La desertificación transmuta el mundo qua mundo en un no-mundo de sustancias inertes e inconexas.

Para explicar la profundidad del efecto que las tormentas de arena ${ }^{26}$ tienen en la destrucción de la potencialidad política de los espacios vinculantes, Arendt recurre a la metáfora del anillo de hierro. El desierto totalitario se convierte progresivamente en un único ente monstruoso por medio del cual se pretende que la humanidad quede representada. La metáfora del anillo de hierro simboliza esta transformación. La pluralidad queda disuelta y los seres humanos se han convertido en los eslabones que conforman los grilletes que los anclan a ese desierto por el que están condenados a vagar. Por medio del terror la arena se solidifica en torno a los seres humanos, envolviéndolos en estos anillos de hierro y haciendo efectiva la dominación totalitaria. El terror hace posible la dominación total «cuando se torna independiente de toda oposición; domina de forma suprema cuando ya nadie se alza en su camino [...]. El terror es la esencia de la dominación totalitaria» ${ }^{27}$.

Los mecanismos específicos del totalitarismo, como el terror, son los responsables del vaciamiento de la vida pública y de la deshumanización estructural que sufren los seres humanos con una eficacia nunca antes experimentada. La novedad del totalitarismo con respecto a la dominación tiránica típicamente moderna es su capacidad de alienación superlativa del mundo, tanto física como moral, de los diferentes ámbitos y modos de la vida humana ${ }^{28}$.

La clave del totalitarismo reside en que su desierto se funda en una persistente e irrefrenable puesta en movimiento donde lo único que es permanente es el cambio, donde la antańo estable realidad pasa a caracterizarse por una irrefrenable e imprevisible volatilidad, lo que nos hace perder las amarras que nos conectan con el mundo y con nuestros semejantes ${ }^{29}$.

El avance del desierto no solo se percibe de manera extensiva en los espacios relacionales, sino que también se produce en lo que Arendt denominó como el desierto de nuestra interioridad. El proceso de deshumanización que se vive en

${ }^{26}$ En la actualidad también sufrimos los azotes de las tormentas de arena, pero se presentan bajo lo que Carl Friedrich y Zbigniew Brzezinski (Cf. Totalitarian Dictatorship and Autocracy, Cambridge, Harvard University, 1956) denominan como "síndrome totalitario» y que Javier Leiva Bustos (Cf. «En la sombra acecha: residuos totalitarios de nuestra era». Astrolabio. Revista internacional de filosofía. 19, 2017, pp. 75-86) expresa como la reproducción total o parcial de un conjunto de síntomas o de prácticas propias de un sistema totalitario en una sociedad definida como no-totalitaria.

27 Arendt, H., Los origenes del totalitarismo (trad. Guillermo Solana), Madrid, Alianza, 2020, p. 623.

${ }_{28}^{28}$ Birulés, F., Una herencia sin testamento: Hannah Arendt, Barcelona, Herder, 2007.

${ }^{29}$ Straehle, E., «De parques, plazas y oasis: una exploración de los espacios políticos en Hannah Arendt». Las Torres de Lucca, 10, 2017, p. 37. 
el desierto totalitario puede llegar a ser tan potente y efectivo que permea la propia piel y puede convertir al ser humano en un extraño de sí mismo.

Para hablar del desierto de nuestra interioridad Arendt diferencia entre la soledad (loneliness) y el aislamiento (isolation). Arendt habla de soledad como el desarraigo y el abandono de toda compañía humana que surge como producto de la atomización y la destrucción de la vida privada. El sujeto que vive en soledad es el sujeto superfluo que carece de la pertenencia al mundo, en tanto mundo común, propio de los movimientos totalitarios ${ }^{30}$. Por otra parte, cuando habla del aislamiento, se refiere a la situación creada tras el desvanecimiento de la vida política donde los seres humanos no pueden actuar ni relacionarse entre ellos en torno a un proyecto de vida común. La relación del sujeto que vive aislado de sí, de otros y del mundo es una relación recíproca. Como lo expresa Arendt: «El hombre aislado, que ha perdido su lugar en el terreno político de la acción, es abandonado también por el mundo ${ }^{31}$.

Los efectos de las tormentas de arena se ven con más claridad en el desierto de nuestra interioridad. En estas tempestades las ráfagas de arena aíslan a los sujetos y les impiden que se vean y se reconozcan los unos de los otros. Este aislamiento no solo afecta al terreno político, sino también al terreno personal: la vida solitaria forzosa erosiona el cuerpo y la psique humana convirtiéndolos gradualmente en la misma arena que los envuelve en las tormentas. Este proceso de deshumanización, que conduce a la aparición de sujetos superfluos, reifica a los seres humanos, los hace parte de la realidad desertificada. De manera análoga a como sucede con los granos de arena que forman los desiertos, los sujetos reificados pasan a formar parte de un no-mundo donde solamente existen colecciones de artículos sin vinculación entre sí. En definitiva, se abandonan al desierto, volviéndose sus habitantes de pleno derecho.

\subsection{El Cese Del Desierto y los oasis}

A pesar de vivir en un período de desertificación, la apuesta de Arendt es detener el avance del desierto. Cree que es posible recuperar la potencialidad política de los espacios vinculantes arrebatada por el desierto. La intención de Arendt no es recuperar un pasado edénico, una tierra prometida, sino interrumpir el proceso de desintegración y atomización de la dimensión relacional humana para, por un

30 En el último capítulo de Los orígenes del totalitarismo (1951) Arendt desarrolla profusamente la caracterización de la soledad. Si bien considera que los sujetos que viven en soledad son la esencia del gobierno totalitario y éstos se relacionan con el desarraigo y la superfluidad, estas características tienen su origen mucho antes en la revolución industrial y se agudizaron con el auge del imperialismo (Cf. Arendt, H., Los orígenes del totalitarismo [trad. Guillermo Solana], Madrid, Alianza, 2020, p. 636). En este sentido, las características del desarraigo y la superfluidad adquirieron nuevas cotas al cristalizar como parte de los mecanismos del fenómeno del totalitarismo

31 Arendt, H., Los orígenes del totalitarismo (trad. Guillermo Solana), Madrid, Alianza, 2020, p. 636. 
lado, cesar la disolución de la vida pública y, por otro, revertir la transformación de los seres humanos en una masa de alteridades o agregado de egos personalistas.

En este juego de metáforas que nos propone Arendt, se vale de la metáfora del oasis vivificante para describir la forma heterotópica que posee el espacio de resistencia desde el que luchar contra la marcha del desierto y poder revertir la despolitización de la vida pública. En palabras de Arendt: «Los oasis se secarán si no los mantenemos intactos, y ellos no son meros lugares de "relax" sino las fuentes dispensadoras de vida que nos permiten vivir en el desierto sin reconciliarnos con él $\aleph^{32}$.

El surgimiento de los oasis tiene dos vertientes. Por medio de la primera, la apertura y el mantenimiento de los oasis nos enseña a respirar en el desierto, puesto que delimita un espacio apto para recuperar la dimensión relacional entre los seres humanos. A través de la segunda, y ésta es la parte que consideramos más relevante, los oasis representan un freno al avance del desierto. El oasis no solo detiene el desierto, mostrándose como un punto de inflexión en su avance, sino que, además, tiene la capacidad de revertirlo.

En su momento originario, los oasis «son aquellas parcelas de la vida que existen independientemente, o casi, de las condiciones políticas ${ }^{33}$ que nos enseñan a respirar, parafraseando a fray Luis de León, lejos del mundanal ruido. Ante el avance del desierto, los oasis actualmente nos enseñan a respirar en un sentido político, haciendo de la existencia de estos frondosos muros verdes una cuestión decisiva ante la desertización del mundo. Pese a la necesidad de mantener los oasis vivificantes, esta difícil tarea no puede dejarse al azar en manos de cualquiera. Este detalle lo apuntó en su momento Arendt cuando afirmaba:

Sólo de aquellos que consiguen resistir el padecimiento de vivir bajo las condiciones del desierto es de quienes podemos esperar que se armen del coraje necesario que se encuentra en la raíz de toda acción, del coraje que convierte a un hombre en un ser actuante ${ }^{34}$.

Sin embargo, la existencia de los oasis está bajo la amenaza constante de ser tragados y fagocitados por la arena del desierto. El mayor peligro para los oasis no es tanto la ferocidad de las tormentas de arenas que recorren el desierto, sino la desesperación de los seres humanos por huir de él. Así lo describe la propia Arendt: «Por la huida de la política arrastramos el desierto a todas partes: religión, filosofía, arte. Arruinamos los oasis ${ }^{35}$. Frente a las tormentas podemos guarecernos en el oasis, podemos soportar los embates de la arena con mayor o menor fortuna.

32 Arendt, H., «Del desierto y los oasis» (trad. Agustín Serrano de Haro). Revista de Occidente, 305, 2006, p. 101.

33 Arendt, H., La promesa de la politica (Ed. Jerome Kohn) (trad. Eduardo Cañas y Fina Birulés), Barcelona, Austral, 2016b, p. 226.

34 Arendt, H., «Del desierto y los oasis» (trad. Agustín Serrano de Haro). Revista de Occidente, 305, 2006, pp. 100-101.

35 Arendt, H., Diario filosófico 1950-1973 (Ed. Ursula Ludz e Ingeborg Nordmann) (trad. Raúl Gabás), Barcelona, Herder, 2018, p. 508. 
En este sentido, hay un margen para la resistencia porque es una fuerza que ataca desde el exterior. No obstante, contra esta huida más sutil y con una menor intensidad de la vida en el desierto, que Arendt denomina como escapismo, es más difícil oponerse debido a que los oasis se arruinan porque son los propios seres humanos quienes introducen la arena del desierto, grano a grano, secándolos y neutralizando su potencialidad política. Para quienes no aceptan la realidad del desierto y solo quieren escapar, entonces el mundo, con independencia de hacia dónde se dirijan, siempre será un desierto.

La forma en la que Arendt articula la metáfora del oasis con la recuperación del mundo es a través de la noción de amor mundi, o amor por el mundo. Esta noción está influida por filósofos clásicos como Demócrito de Abdera, por Epicuro de Samos y Lucrecio ${ }^{36}$, y, a su vez, por el concepto nietzscheano del amor al destino o amor fati ${ }^{37}$. El amor mundi de Arendt es continuador de este amor por la realidad fenoménica del mundo tal cual se nos presenta, sin idealismo ni sublimaciones ${ }^{38}$. El amor por el mundo representa la aceptación, la vinculación y el afecto por la diversidad y las imperfecciones inherentes del mundo. La afirmación radical de la pluralidad de la vida debe traducirse, según Arendt, en un amor existencial y vitalista hacia los demás seres vivos, pero no en un sentido romántico. Arendt definió en una entrada de su Diario filosófico (2018) el amor mundi de la siguiente manera:

Amor mundi: trata del mundo, que se forma como dimensión espacial y temporal, tan pronto como los hombres están en plural; no hace falta que estén los unos con los otros, o los unos junto a los otros, basta la pura pluralidad (el puro entre). Trata del mundo en el que erigimos nuestros edificios y nos instalamos, en el que queremos dejar algo permanente, al que pertenecemos, en cuanto somos en plural. Además, es un mundo frente al cual permanecemos eternamente extrańos, por cuanto somos también en singular, un mundo que en su pluralidad es el único lugar desde el cual podemos determinar nuestra singularidad. Vemos y somos vistos, oímos y nos oyen en el entre. No estamos pegados a la vida, que se agota por sí misma, estamos pegados al mundo, por el que desde siempre nos hallábamos dispuestos a dar la vida ${ }^{39}$.

La metáfora del oasis sintetiza la imagen sistémica de ese espacio vinculante entre los seres humanos no designado topológicamente y propio para la acción, el

36 Cf. Campillo, A., El concepto de lo político en la sociedad global, Barcelona, Herder, 2008.

${ }^{37}$ Esta idea del amor nietzscheano es la fuerza creadora de los seres humanos capaz de romper con la esclavitud de su pasado. Nietzsche en la obra póstuma Ecce Homo (1908) expresa el amor fati como «el no querer que nada sea distinto ni en el pasado ni el futuro ni por toda la eternidad -todo idealismo es mendacidad frente a lo necesario-, sino amarlo...» (Cf. NiETzsche, F., Ecce Homo [trad. Andrés Sánchez Pascual], Madrid, Alianza, 2011, p. 71).

${ }_{38}$ Mientras que Arendt promueve una erótica por la vida, la tradición filosófica de la que es crítica impone una tanatofilia en su concepción del mundo (aspecto que continuó en sus análisis Michel Foucault).

39 Arendt, H., Diario filosófico 1950-1973 (Ed. Ursula Ludz e Ingeborg Nordmann) (trad. Raúl Gabás), Barcelona, Herder, 2018, p. 524. 
juicio y la reflexión política. Esta metáfora le permite comprender a Arendt, por contraposición, el alcance y la profundidad de la amenaza que ejerce sobre la potencialidad política de los espacios vinculantes la existencia del desierto, no ya de manera física, sino también en la interioridad humana, en un mundo marcado por el fenómeno generalizado de extrańamiento del mundo.

\section{EL DRAMA HISTÓRICO DEL EXTRAÑAMIENTO DEL MUNDO}

Por medio de esta familia de metáforas subyace una preocupación transversal en el pensamiento de Arendt: la experiencia del fenómeno de extrańamiento del mundo (Weltentfremdung), que caracteriza la condición humana desde la modernidad. Arendt vive la experiencia de este fenómeno como si se tratara de un drama histórico que refleja una situación de pérdida del mundo, ya que lo que está en juego es el declive de la dimensión relacional entre los seres humanos, haciendo que sean «incapaces de formar un espacio auténticamente común y plural» ${ }^{40}$. Este fenómeno, catalogado por Arendt como un fenómeno negativo, representa un síntoma de una crisis mucho más profunda ${ }^{41}$.

Sorprende el hecho de que Arendt no recurra el término alemán «Weltfremdheit» (desconocimiento del mundo) para referirse a este fenómeno, sino que componga un neologismo que une el término anteriormente mencionado con «Entfremdung» (alienación). De tal modo que con el término «Weltentfremdung» intenta plasmar cómo el fenómeno de extrañamiento del mundo, que para Arendt es un proceso histórico heterogéneo que nace en el mundo moderno, no solo representa un alejamiento de la realidad fenoménica, sino también una enajenación patológica del mismo. Como consecuencia, este fenómeno convierte a los seres humanos en extranjeros de sí mismos y de su entorno.

En su análisis, Arendt se percata de algo sorprendente: no se puede recurrir a la tradición filosófica debido a que la falta de conocimiento del mundo es un mal endémico, una deformación profesional que comparten la mayoría de los filósofos. La percepción actual de la política y, por tanto, de la relación entre los seres humanos y su entorno continúa mediada por la concepción moderna de la política epistemológica. Por esta razón, Arendt debe recurrir a nuevos enfoques.

Para comprender la profundidad de este fenómeno recurrimos en este punto a Günther Anders ${ }^{42}$ y su concepto de antiquiert, traducido en español como obso-

40 Straehle, E., «De parques, plazas y oasis: una exploración de los espacios políticos en Hannah Arendt». Las Torres de Lucca, 10, 2017, p. 39.

${ }^{41}$ Venmans, P., El mundo según Hannah Arendt: Ensayos sobre su vida y obra (trad. Laura Alonso Padula), Madrid, Punto de Vista, 2017.

${ }^{42}$ Cf. Anders, G., La obsolescencia del hombre. I, Sobre el alma en la época de la segunda revolución industrial (vol. 1) (trad. Josep Monter Pérez), Valencia, Pre-textos, 2011a; y Anders, G., La obsolescencia del hombre. I, Sobre el alma en la época de la segunda revolución industrial (vol. 2) (trad. Josep Monter Pérez), Valencia, Pre-textos, $2011 b$. 
lescencia. Anders nos presenta un panorama pesimista sobre la relación humana con el vertiginoso desarrollo técnico donde el cuestionamiento de esta relación es tan relevante en su momento como ahora: ¿podemos seguir el ritmo emocional y espiritual del progreso hecho por el hombre? La respuesta de Anders es un rotundo no. El impacto en la psique humana y en la sociedad del desarrollo técnico es abrumador y, podríamos decir, deshumanizador. El mundo creado por los seres humanos ha sobrepasado las capacidades de sus creadores para controlarlo. De ahí que Anders hable de los seres humanos como seres extraños en su propio mundo, como seres obsoletos o anticuados (antiquiert).

Anders, de una forma casi profética, se adelanta varias décadas a los análisis críticos sobre los medios de comunicación, el desarrollo técnico, la sociedad de consumo y el capitalismo postindustrial de autores como, por ejemplo, Marshall McLuhan, Neil Postman, Zygmunt Bauman, Slavoj Žižek o Byung-Chul Han. Para Anders las categorías de espacio y tiempo han dejado de ser condiciones de percepción, como sucedía con Immanuel Kant. En su lugar, se han convertido en condiciones de invalidez para la realización del mundo y la construcción de la identidad humana. Para mantener en circulación el imperativo actual del consumismo ${ }^{43}$, el espacio y el tiempo entre la necesidad y su satisfacción deben acortarse lo máximo posible. El problema que encuentra Anders en este proceso de acortamiento del tiempo y el espacio es que los seres humanos se encuentran con un exceso de tiempo con el que no saben qué hacer.

En su análisis, Anders describe cómo los productos son reemplazados cada vez más rápido por otros modelos actualizados. La cuestión determinante es que la necesidad para utilizar estos nuevos modelos no se establece tan rápido. Razón por la cual es el propio sistema de producción el que genera las necesidades artificiales y ficticias para incrementar su consumo a través de la publicidad, las estrategias de marketing y neuromarketing, las redes sociales y los medios de comunicación. Los productos nuevos ya se producen como chatarra, porque tan pronto como están en el mercado, la publicidad y el marketing nos dicen que ya están desactualizados. Vivimos en un mundo de usar y tirar. Los objetos que poseemos ya no tienen tiempo para convertirse en nuestra propiedad. Los productos se están volviendo líquidos, en términos baumanianos, y, con ellos, los seres humanos, pues son incapaces de seguir el ritmo de este progreso técnico. Para hacer frente a esta situación los seres humanos se convierten paulatinamente en los productos que consumen y, por ende, se impregnan de la lógica que rige en ellos ${ }^{44}$.

${ }_{43}$ Para hablar del imperativo que subyace en el consumismo actual y, por ende, es el motor del capital, seguimos la explicación que ofrece Slavoj Žižek: «El capital tiene que circular, reproducirse, expandirse, multiplicarse, y por esta meta puedes sacrificar lo que sea, hasta nuestras vidas, la naturaleza y demás» (Vid. Fiennes et al., The Pervert's Guide to Ideology [Guía perversa de la ideologia] [película documental], Reino Unido, Films 4, 2012).

${ }_{4}$ Para profundizar en esta idea, véase Quintero Martín, S., «La sublimación de la dialéctica del placer en el consumismo global», en José Manuel Chillón et al. (eds.), Antropología de la comunicación: Acción y efectos en la literatura y los «media» (pp. 51-62), Madrid, Fragua, 2019. 
Ante esta situación de obsolescencia del ser humano, ante este drama histórico de extrańamiento del mundo, Arendt, con su obra, quiso contribuir a igualar (o por lo menos reducir) la distancia entre el progreso técnico y la capacidad humana para interactuar. Un ejemplo de ello es La condición humana (1958) donde Arendt realiza su propuesta de renovación del lenguaje para expresar, reflexionar, juzgar y actuar en la realidad fenoménica actual, estableciendo un marco de pensamiento que no esté desfasado ni dependa en gran medida de términos o visiones tradicionales. La intención de Arendt es pensar nuestra realidad fenoménica desde su propia fragilidad sincrónica, sin alusiones utópicas al futuro ni sublimaciones de un pasado mejor. En definitiva, Arendt reflexionó desde la fragilidad de su tiempo, aceptando de lleno el espíritu de la época (Zeitgeist), para presentar la «ruptura entre el pensamiento tradicional y la experiencia contemporánea» ${ }^{45}$.

Los análisis de Anders y Arendt ${ }^{46}$ sobre el fenómeno moderno del extrañamiento del mundo $y$, sobre todo, el hincapié en el desarrollo exacerbado que ha adquirido en el siglo Xx se complementan para darnos una imagen mereológica ${ }^{47}$ mucho más completa y compleja que sería imposible por separado. El escepticismo pesimista de Anders, ${ }^{48}$ por un lado, en torno al panorama que nos ofrece el desarrollo tecnológico dentro del marco de producción capitalista y el aparataje teórico-conceptual de Arendt, por otro, sobre la comprensión de la condición humana y las actividades propias de los seres humanos (labor, fabricación y acción). Estas perspectivas se reflejan en el hombre obsoleto andersiano y en el auge del Homo faber y el animal laborans arendtianos.

Ambos autores coinciden en que los espacios vinculantes entre los seres humanos se encuentran en problemas. El fenómeno de extrańamiento del mundo se presenta como el síntoma que refleja una crisis que afecta a los pilares que sustentan el mundo moderno. Este panorama abre la barbarie a los espacios vinculantes y, como consecuencia, se disuelven las esferas de lo público, lo plural y lo común. La otrora dimensión relacional adquiere las capacidades inversas: disgrega y atomiza, en

45 Birulés, F., La especificidad de lo politico: Hannah Arendt, Valencia, Episteme, 1995, p. 1.

46 Ambos autores emplean un estilo alejado del academicismo ortodoxo de sus maestros fenomenólogos (Edmund Husserl y Martin Heidegger) para expresarse por medio de un lenguaje más cotidiano, cercanos al periodismo y al ensayo. En Anders hablamos de la filosofía ocasional y en Arendt del periodismo intelectual.

47 El lógico y filósofo polaco Stanislaw Leśniewski elaboró a comienzos del siglo xx la formalización exitosa de la mereología como una teoría o estudio para explicar las relaciones de los todos y las partes, y las interacciones posibles entre las diferentes partes (Cf. SRZEDNICKI, J.T.J., Rickey, V.F. y Czelakowski, J., Lesniewski's Systems Ontology and Mereology, La Haya, Martinus Nijhofl, 1984). Por medio de las imágenes mereológicas pretendemos expresar y visibilizar las redes de relaciones que existen entre los diferentes elementos o ingredientes que componen la realidad, en concreto lo aplicamos para profundizar en las relaciones entre los sujetos y el conjunto de su entorno para conocer y comprender el mundo.

48 Anders no llega a planteamiento neoluditas como, por ejemplo, los de Theodore Kaczynski plasmados en su obra La sociedad industrial y su futuro (2011), conocido popularmente como el Manifiesto Unabomber. Por su parte, Anders plantea una duda razonable, aunque pesimista, sobre el desarrollo técnico. 
lugar de unir. Pertenecer a este mundo de barbarie moderna desertifica el entorno y deshumaniza a todos los involucrados.

Por así decirlo, la barbarie de nuestros tiempos no tiene tanto que ver con quienes hablan una lengua distinta e ignoran la nuestra sino que se hace mucho más cercana, al afectar a quienes pese a su posible proximidad no son capaces de tejer un mundo en común ${ }^{49}$.

En el siglo xx se hizo palpable el paroxismo al que los elementos característicos de la modernidad fueron llevados. La subjetivación del poder se volvió el culto al líder totalitario. La idea de progreso estableció regímenes de apartheid y discriminación que perduran hasta nuestros días. La creencia incondicionada en la razón solo permitió mostrar una narración monocroma de la realidad. El proceso de industrialización hizo orbitar la vida en torno al razonamiento economicista y transformó la esfera social en una sociedad de masas.

A lo largo de la modernidad Arendt encontró diferentes formas en las que el fenómeno de extrañamiento se hace presente en el mundo. El primero, y más extendido, es la glorificación de la labor y la vida. Conforme a la óptica arendtiana el interés por el mundo, es decir, el amor mundi, es sustituido por un amor egoísta hacia el cuidado de todos los aspectos de la vida (promovidos por el consumismo). Contrariamente a esta idea, la libertad no está ligada a satisfacer este ámbito de la necesidad, sino a trascenderlo. En otras palabras, la libertad, en tanto libertad de consumir, es una libertad ficcional, pues en realidad ancla la existencia a estas necesidades y reduce la condición humana a la animalidad propia de la labor. Se ha invertido la compresión de la vida entre zoé (vida biológica) y bios (vida biográfica). Arendt expresa esta idea diciendo que «casi hemos logrado nivelar todas las actividades humanas bajo el común denominador de asegurar los artículos de primera necesidad y procurar que abunden $"^{50}$ (Arendt, 2016a, p. 136).

La glorificación de la labor y la vida se realiza no solo a costa de la acción, elemento esencial en la fenomenología arendtiana, sino también del trabajo. El animal laborans se convierte en el centro de la escena pública moderna donde la política ha sido sustituida por el razonamiento economicista. Este apoderamiento de la economía transforma las relaciones humanas y las hace depender de las necesidades, marginando en este proceso a la acción. Los seres humanos, en tanto animal laborans y parte de la sociedad de masas, se convierten en trabajadores y consumidores que viven en el desierto de la irreflexión.

La lógica del razonamiento reflexivo dicta que a cada necesidad le corresponde un producto (manufacturado en forma de bien o servicio), por tanto el consumo se vuelve una condición básica e innegociable de la existencia humana,

49 Straehle, E., «De parques, plazas y oasis: una exploración de los espacios políticos en Hannah Arendt». Las Torres de Lucca, 10, 2017, p. 39.

50 Arendt, H., La condición humana (Ed. Manuel Cruz) (trad. Ramón Gil Novales), Barcelona, Paidós, 2016a, p. 136. 
ocupando el lugar de la labor. Al convertirse en parte indisociable del ámbito de la labor, los productos creados como objetos de consumo adquieren sus mismas características ${ }^{51}$. El propósito de la labor es producir para satisfacer en un plazo inmediato. La labor tiene un carácter repetitivo y sin particular notoriedad pública porque se realiza con la intención instintiva de preservar el cuerpo.

La cuestión es que una sociedad de consumo posiblemente no puede saber cómo hacerse cargo de un mundo y de las cosas que pertenecen de modo exclusivo al espacio de las apariencias mundanas, porque su actitud central hacia todos los objetos, la actitud del consumo, lleva la ruina a todo lo que toca ${ }^{52}$.

La segunda forma de extrańamiento, que es una variante de la primera, se presenta como «la nefasta influencia que emite el trabajo cuando adopta la forma de tecnología impuesta " ${ }^{53}$. En la era de la tecnología moderna el carácter duradero y de permanencia del trabajo ha desaparecido. Arendt entiende el trabajo como un proceso de reificación que permite crear el mundo humano (en oposición a la labor, que lucha contra la naturaleza) ${ }^{54}$. Se caracteriza por su naturaleza productiva, artificial y planificada. El valor de la fabricación está marcado por la utilidad, es decir, por el uso como medio o herramienta de lo producido.

En cambio, en el mundo moderno (y más aún en la actualidad) estas características no se cumplen, sino que, por el contrario, se produce una «unificación rítmica del cuerpo laborante con su utensilio ${ }^{55}$. Es en este proceso de unificación donde nace el Homo faber. Arendt no desarrolla el alcance y las ramificaciones de esta concepción del trabajo, pero encontramos un hilo conductor para completarla en la biopolítica de Michel Foucault ${ }^{56}$ y en la psicopolítica de Byung-Chul Han ${ }^{57}$.

51 Dermot Moran describe perfectamente cuáles son las características de la labor: «La labor incluye el círculo perenne de la vida y la muerte, en el que se busca la alimentación, el vestido, la protección de los elementos, y así consiguientemente» ( $C f$. Moran, D., «Hannah Arendt. La fenomenología de la esfera pública», en Dermot Moran, Introducción a la Fenomenología [Ed. Gustavo Leyva] [trad. Francisco Castro Merrifield y Pablo Lazo Briones] [pp. 270-300], Barcelona, Anthropos, 2011, p. 293).

52 Arendt, H., Entre el pasado y el futuro: ocho ejercicios sobre la reflexión politica (trad. Ana Poljak), Barcelona, Península, 1996, p. 223.

53 Venmans, P., El mundo según Hannah Arendt: Ensayos sobre su vida y obra (trad. Laura Alonso Padula), Madrid, Punto de Vista, 2017, p. 116.

${ }^{5}$ Cf. Moran, D., "Hannah Arendt. La fenomenología de la esfera pública», en Dermot Moran, Introducción a la Fenomenología (Ed. Gustavo Leyva) (trad. Francisco Castro Merrifield y Pablo Lazo Briones) (pp. 270-300), Barcelona, Anthropos, 2011.

55 Arendt, H., La condición humana (Ed. Manuel Cruz) (trad. Ramón Gil Novales), Barcelona, Paidós, 2016a, p. 165.

${ }^{56}$ Cf. Foucault, M., Historia de la sexualidad, 1: La voluntad de saber (Eds. Julia Valera y Fernando Álvarez-Uria Rico) (trad. Ulises Guiñazú), Madrid, Siglo XXI, 2005; y Foucault, M., El nacimiento de la biopolitica: curso en el Collège de France (1978-1979) (trad. Horacio Pons), Madrid, Akal, 2009.

57 Cf. Han, B., Psicopolitica. Neoliberalismo y nuevas técnicas de poder (trad. Alfredo Bergés), Barcelona, Herder, 2015. 
La cuestión que sí pone de manifiesto Arendt es que tanto la labor como la fabricación, orientadas por la técnica y el economicismo, han usurpado el espacio que de suyo le corresponde a la acción y, más concretamente, a la acción política.

La consideración arendtiana del trabajo coincide con la preocupación andersiana por el desarrollo técnico porque ambas perspectivas están mediadas por el empleo o imposición de la tecnología. Ambos autores concuerdan ante la pregunta ¿las máquinas siguen estando a disposición del mundo o, por el contrario, los procesos tecnológicos controlan el mundo a costa del propio mundo? ${ }^{58}$. A pesar de la respuesta que tanto Arendt como Anders pudieran dar, no hay que olvidar que el fenómeno de extrańamiento del mundo no es irreversible. Como hemos visto con la metáfora del oasis, aún hay lugar para otra forma de entender y construir el mundo.

La respuesta a la pregunta de la que parte la reflexión de Arendt: ¿por qué hay alguien y no más bien nadie?, es en cierto modo sencilla de expresar, pero su calado atañe a la concepción actual sobre el propio fenómeno de lo político. Sigue habiendo alguien, a pesar de que parece que cada día los seres humanos están más cómodos viviendo en el desierto, porque existe la acción. Más concretamente, porque la acción se encuentra ontológicamente enraizada en la humanidad. Aún es posible esperar la aparición del milagro de la peripecia, de ese «algo inesperado, imprevisible $y$, en último término, inexplicable causalmente ${ }^{59}$ que nos permite hablar de un mundo común.

ReCibido: mayo de 2021; ACEPTAdo: julio de 2021

58 Venmans, P., El mundo según Hannah Arendt: Ensayos sobre su vida y obra (trad. Laura Alonso Padula), Madrid, Punto de Vista, 2017.

59 Arendt, H., ¿Qué es la politica? (Ed. Fina Birulés) (trad. Rosa Sala Carbó), Barcelona, Paidós, 2015, p. 64. 
